\title{
Designing and Using a MySQL Database for Human Resource Management
}

\author{
Evaristus Didik Madyatmadja*, Chelsea Adora
}

Information Systems Department, School of Information Systems, Bina Nusantara University, 11480, Indonesia

\begin{tabular}{l} 
A R T I C L E I N F O \\
\hline Article history: \\
Received: 04 October, 2019 \\
Accepted: 26 November, 2019 \\
Online: 12 December, 2019 \\
\hline Keywords: \\
Database Design \\
Relational Database \\
HRIS
\end{tabular}

\begin{abstract}
A B S T R A C T
In this paper, we would like to discuss the methods and ideologies used to create a database to be used for Human Resource purposes. Because we want this database to be accessible anywhere at any time, it is safe to conclude that an internet-based (web-based) database would work best, therefore we chose MySQL as the database management system. Before diving deep into the making of the database itself, it is important to understand certain basics of database design and the phases of the database life cycle itself. This paper will conclude on a few of the basic things to understand before designing a database for Human Resource Management on MySQL.
\end{abstract}

\section{Introduction}

Every company in the world has more than one person working for its purpose. These people involved in a company are what we know as employees, human resources to a company that drives the company closer to its goal and purpose. As a company grows, it will need more employees to expand its wings [1], and to some Human Resource Managers, it is a pain to organize and keep tabs on all the human resource data. The bigger the company, the harder the Human Resource Managers will have to work to keep the data accurate and tidy.

At the end of 2018, the Economist Intelligence Unit reports that $82 \%$ of companies in the world (taking samples) plan to start using or increasing the use of a human resource database. These companies also realize the importance of good management of human resource data by implementing an employee database.

Not that doing all the human resource management work manually is painful and tiring for the Human Resource Managers and administrators, it may also cause the company and owner some great loss. Imagine having a construction company with hundreds of workers working different shifts and all their attendance data must be recorded manually using paper and pen without supervision. The workers might put in false data on their attendance record resulting in a big loss for the company where the company pays a big amount of money for salaries and wages while the construction project itself has not progressed much.

Another problem is that by doing every human resource process manually, it will take longer for the Human Resource

*Evaristus Didik Madyatmadja, J1 KH Syahdan No. 9, Palmerah, Jakarta, Indonesia, Contact No: +62811254952, Email: emadyatmadja@binus.edu
Manager or administrator to work on the employees' payroll calculation. Not to mention, there is a possibility that there may be an error in the payroll calculation due to the manual work of reading and counting the attendance data on a calculator to produce a paycheck.

All the problems stated above may be solved by having a database that covers human resource management, from employee personal data, employee attendance data, to their payroll data. Even in Hong Kong, industries have confirmed that one of the best things they gained by having a human resource computer system in assisting their human resource activities is the seamless flow of data [1]. By having all human resource data recorded in an organized database, the accuracy of data is definite, resulting in accurate budgeting for human resources (salaries \& wages). This also means that the Human Resource Managers can work faster with the human resource database working alongside as an assistant [2].

When making a database for a specific concern, like human resources perhaps, assessment of the needs of the company is needed. For more universal use, a free, open-source database will be discussed further, along with its web-based benefit. Because MySQL is web-based and the fact that it works on a server [3], the human resource database will be accessible anywhere and at any time if there is an internet connection, that is if the company decides to use it as an internet-based system. Either way, by using the localhost or the internet, MySQL has a more general purpose and can serve both needs.

According to a company in Indonesia that has yet to use a human resource database, employee data storage, especially those related to attendance, still has many shortcomings because 
attendance data collection (including overtime calculations) is still done manually. Because attendance data collection is still done manually using paper and pens, fraud often occurs in filling attendance and overtime information. This fraud resulted in huge losses for this company because the nominal salary paid to employees of this company is not in accordance with the development of the project. In addition, there were also errors in entering data from paper into digital form (Microsoft Excel). As a result of these errors is the administrator must check the data that has been entered a few times and correct errors that exist to ensure that the data entered is correct. For this reason, this company requires a database system that can record employee attendance factually to reduce these losses and facilitate the work of the human resource department or commonly known as HRD.

\section{Definition of Human Resource Information System}

Human Resource Information System (HRIS) is a software that keeps all data regarding human resource management activities, from the employee master data, employee attendance data, payroll data, even their performance (for more advanced measures) in a centralized manner. Improvement in performance levels is very much possible when using a proper Human Resource Information System, and thus allows consultation activities to take place, such as discussion and coaching or mentoring [4]. Using HRIS also gives us data that are more accurate and consistent, therefore resulting in accurate processed data [5]. Human resource information systems (HRIS) are "combinations of databases, computer applications, and hardware also software needed to collect / record, store, manage, send, present, and manipulate data for human resources", as stated in [6].

Not using an automated Human Resource System may lead to fraud and data inconsistencies. Using an automated Human Resource System on the other hand, helps an organization in strategicly organizing human resource data, as well as help toplevel management in human resource related decision making [7]. An automated Human Resource System has been proven to bring benefits such as effectiveness and efficiency in the Human Resource Department, as there may be a downsizing in the HR staff [8].

\section{Development of Human Resource Information Systems}

Human Resource Information Systems may seem like a senior technology to some, but for companies in developing countries, HRIS may seem relatively new. Technology has brought different results in terms of effectiveness in helping manage human resources. This depends on the abilities of the user in using the technology itself [9].

The size of the company impacts what gains and losses will be received by the implementor of the HRIS. Larger companies which already possess technological properties will most definitely feel more benefits as they can retrieve important staff data in a flash. Small businesses may not have the resources and technical competence to do such things.

A simple and good alternative to creating a customized HRIS is to use a pre-packaged HRIS software instead. To buy the most suitable package for a company, it is necessary to contact the supplier or vendor and compare all of the candidate products to find the HRIS product that best suits the requirements of the business.

Most HRIS implementations fail due to the lack of commitment from senior managers. Without having the support of senior managers, the implementation of the HRIS will most likely not be prioritized and the resources needed will not be provided to be used [10]. One of the most important resources that can be provided by senior managers are financial resources, which plays a critical role in an HRIS implementation in an organization [11]. Senior managers need to understand exactly why an HRIS in managing the organization's human resource activities is important, and the business values they will gain after implementing an HRIS [12]. By understanding such matters, senior managers may support the implementation by providing a bigger budget. This money provided by senior managers will not only play a role in the implementation, but also operation and maintenance. More promotional efforts and action plans are needed to show the specific benefits of using HRIS if senior management knows the benefits that can be achieved by implementing HRIS.

\section{Research Methodology}

This research regarding a Human Resource Database System uses the Literature Review Methodology. A literature review is a compilation of theories, findings, and research results used as references in a research to get a better understanding on a problem and its proposed solution.

A Literature Review is more or less analysis in the form of criticism (construction or fall) of the research being done on a specific topic or question in a part of science. The literature review is a scientific history of a particular problem.

Materials for the literature review may be found from trusted sources on the internet, books, articles, newspapers, or other sources that are confirmed as press. A good review of the literature should be relevant, current and adequate. The theoretical basis, the theoretical review and the literature review are several ways of conducting the literature review.

- Formulating the problem. Choose a topic that matches your topic and interest. The problem must be written completely and accurately.

- Literary search. Look for relevant literature for research. Get an overview of research topics. When looking for related materials from previous studies, it is important to make sure that the source of these materials is trusted press, offline or online.

- Evaluating the data. Not only literature, but data can also be obtained from previous studies. These data, qualitative or quantitative, need to be analyzed according to the problem statement of the research.

- Analyzing and interpreting. Discuss and find and summarize the literature. After gathering all the materials and data, start analyzing everything gathered from the point of view of the problem. Summarize all the materials and propose a solution based on all the trusted materials. 


\section{Introduction to Database}

According to [13], A database is an integrated collection of data that is stored, managed and centrally controlled. Databases usually store information about entities in large numbers (tens, hundreds, to thousands of entities). Information stored in the database is the entity's attributes (for example, name, price, and account balance) and the relationship of an entity with other entities (for example, which orders belong to which customers). The database also stores descriptive information about the data, such as field names, allowable value restrictions, and controls access to sensitive data items.

The database has its own language called query. There are several kinds of languages in the query where the explanation is as follows:

- Data Definition Language (DDL), which is a language that governs the making of structures from a database. DDL is not related to data that fills in the database structure. Some examples of DDL are CREATE, DROP, and ALTER.

- Data Manipulation Language (DML), which is a language that governs changes to database contents. Some examples of DML are INSERT, UPDATE, DELETE, and SELECT.

- Data Control Language (DCL), which a language that regulates anyone who can access a part of the database designed. Some examples of DCL are GRANT and REVOKE.

\section{Database Management System}

According to [14], a Database Management System (DBMS) is a software system that is created specifically to facilitate the management of databases. A Database Management System is a software that allows users to create, access and manage a database. In the database approach, each file in each department is stored on a database server with a new designation, namely the table. Each program can then access parts of the database as necessary.

At the moment there are many database management systems available to meet the business needs of every company. Each database management system has advantages and disadvantages of each, where the decision to choose the right candidate is certainly based on the scale, budget, and needs of the company itself. According to a survey conducted by DB-Engines in May 2019, the most commonly used database management system is Oracle, MySQL, and Microsoft SQL Server.

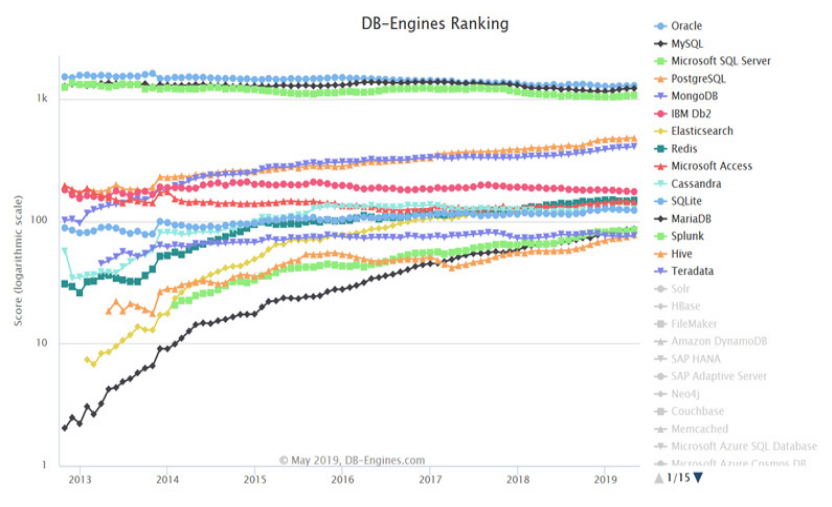

Figure 1: DBMS Ranks by DB-Engines
In accordance with the needs and business scale of the organization, MySQL is one of the best candidates to become a database management system from an employee database that will be built and implemented. That's because MySQL is not too complex and sufficient for the business scale of the organization which consists of hundreds of employees, unlike Oracle which is very complex and is more aimed at companies with a much larger scale. Because the application to be built is also web-based, so a database that is suitable for use and in accordance with the scale of the company the organization is MySQL. In addition to these factors, MySQL is very affordable compared to Oracle, where MySQL is a Database Management System (DBMS) that is free to use and is licensed by the GNU General Public License, while Oracle is a paid DBMS (Express version can be accessed free of charge, but features -The DBMS features are limited and only recommended for educational and testing use).

MySQL is a database management system that is used through the web where MySQL operates on a server [3]. This provides a good opportunity for writers to develop prototypes related applications using a web base. Our desire to build a prototype of a web-based application is supported by the Information Services Group's statement in 2018, namely that $48 \%$ of professional workers in the field of Human Resources want to switch to internet-based Human Resource applications, or familiarly known as the cloud.

\section{Database Life Cycle}

In order to design a database that is usable in the long run, there are a few steps that should be followed. One of the most general and common guidelines used is the Database Life Cycle. The steps of the Database Life Cycle are as follows.

\subsection{Database Planning}

Database Planning include management activities that enable the Database Life Cycle's success in effective and efficient implementation. This step involves defining the mission statement dan mission objective. The Mission Statement defines the main purpose of the database application, the purpose of this database design project, and clarifies the flow of making a database application so that the design can be carried out effectively and efficiently. Examples of mission statements are "The purpose of creating a database for XYZ Inc. is to facilitate all the activities of XYZ Inc. clients who use their services and also their daily staff so that the business processes carried out can run efficiently with the availability of information that is complete in real-time. ". Mission Objectives are written as a list that contains further details of the mission statement. These further details can be in the form of general features that will be developed in the new database system. One example of a mission objective is "To maintain (insert, update, delete) data on the hotels, rooms, guests, and bookings".

\subsection{System Definition}

System Definition is the process of determining and elaborating the boundaries and scope of the database system development project and the main user view of the database system. What is meant by the user view here is the access rights of a role (such as manager or supervisor) or department (such as 
marketing or human resources) to data entities in the database to be developed.

\subsection{Requirements Collection and Analysis}

Requirements Collection and Analysis is the process of gathering the needs of users or companies so that the database system is designed right on target and in accordance with company needs [14]. These company needs are documented in the requirements specifications. A few approaches that may be used here are the Centralized Approach, View Integration Approach, or both of them combined. Some of the techniques said before can be carried out in accordance with the scope of the project and the company, as well as the conditions of the project itself, such as the availability of time and resources that support research. All techniques can be used for a project, but a project can only use one or two because the scope is too large or resources are not available, and time is limited.

\subsection{Database Design}

Database Design is basically the designing of the database from the conceptual, logical, and physical model. There are a few approaches to this step which are Bottom-up, Top-down, Insideout, and Mixed [14]. The Bottom-up Approach is an approach where data modeling starts from the properties or attributes, then a larger entity is identified. The bottom-up approach starts from the initial attributes (entities and relationships) that are analyzed by the relationship between attributes, then relationships are formed that represent the types of entities and relationships between entities. This approach is suitable for simple database designs with relatively fewer attributes. The Top-down Approach is an approach where data modeling starts from large entities first, then attributes are identified. The top-down approach starts with developing a data model that consists of several or many entities and relationships, then identifies low-level entities, relationships, and associations between attributes. This approach is explained by the Entity Relationship Diagram, which starts with the identification of entities and the relationships between entities. The Inside-out is an approach where the modeling of data starts from a larger cup first, then a smaller cup. This approach is related to the bottom-up approach, but it is slightly different from the initial identification of the main entity which then spreads to the entities, relationships, and other attributes that were first identified. The Mixed Approach is a combination of the Top-Down and BottomUp approach where both are used for different aspects and then a merging of the results of the data model from both.

\subsection{DBMS Selection}

DBMS Selection is a stage in the Database System Development Life Cycle where there will be a comparison between outstanding DBMS products and the selection of DBMS that is deemed most suitable for database design projects. This DBMS selection can also be done before the Database Design stage to ensure the physical database design of the database is designed in more detail and in accordance with the technical needs of the selected DBMS. Several aspects of the company must be taken into consideration when choosing a DBMS to be the foundation of the database to be built, such as the scale of the company's business and the company's budget for the database design project itself. The selection of the DBMS must also consider the needs and requirements of the company that have been collected at the requirements collection stage. Each DBMS has its own features, strengths, and weaknesses, so the chosen DBMS must be truly in accordance with the needs of the company. The main steps for selecting a DBMS are defining reference study terminology, registering two or three products, product evaluating, and choosing one that best fits the needs and create product reports for senior management.

\subsection{Application Design}

Application design is a process in which the user interface and features of a database application are described in detail. It is very important to make the application as user-friendly as possible to ensure the database will be used in the future [15-16]. In the application design process, there are two main processes that are key to the application design, the transaction design and the user interface design. The Transaction Design is a transaction flow in which there are actions that can access or change the contents of the database. In other words, transaction design is the entire business process in the context of a company that can access or change the contents of the company database. In general, transaction design can be done by creating a Use Case Diagram, and sometimes an Activity Diagram to describe the flow of the overall process. User Interface Design in the other hand is the process of designing the final appearance of a database system that will be seen by end-users. The main purpose of the user interface design activity is to produce a display design that is easy to use by users or more familiarly referred to as user-friendly.

\subsection{Prototyping}

Prototyping is an activity of making a prototype of the system as a whole. A Prototype itself is a working model or model that serves to display some features or functionality of the entire database system that is built [14]. A prototype is a tangible artifact, not something abstract. In general, there are two types of prototypes, namely Offline or paper prototype and Online or prototype software. The purpose of making a prototype is to ensure that all the needs and expectations of the end-user are met before making a real application. There are several techniques that can be used to make prototypes, some of which are as follows:

- Representation: Representation is a representative of a database system that as a whole is quite large. The representation can be in the form of a simple drawing or paper sketch or computer simulation.

- Precision: Precision means that the prototype that is designed must be determined whether it will be made in detail, or made in outline only to introduce some key features to the end-user.

- Interactivity: Interactivity refers to the interaction that occurs between the user and the prototype, whether only watch-only or whether the prototype is fully interactive Interactivity is closely related to Representation.

- Evolution: Evolution refers to the use of the prototype itself. There are two types of prototypes in this evolutionary context, throwaway and iterative. Throwaway means that the prototype is made only as presentation material that will not be used again after the 
presentation to the user. Iterative: Iterative means that the prototype that is made will continue to be developed until it becomes an application that will actually be used operationally by the company.

\subsection{Implementation}

Implementation is the physical realization of database design and software design. At this stage, the realization of the database is achieved by using Data Definition Language (DDL) from the selected DBMS. Apart from the database side, the creation of Graphical User Interface (GUI) is also done as a form of implementation in terms of its application.

\subsection{Data Conversion and Loading}

Data Conversion and Loading is an activity to fill tables that have been made before with real company data [14]. Data Conversion and Loading is a mandatory activity so that the database system can be used operationally by the compay. Conversion here can mean changing the data format from one format to another so that it can be used in a new database system. Company data itself can be retrieved from legacy systems or even paper-based manual records. Including real data is somewhat important, even if it is still in the early stages of the process. Not having them included from the start may cause the developers to modify everything they have built just to make it compatible with the data [17].

\subsection{Testing}

Testing is an activity to run a database system that is designed with the aim of finding errors or errors that exist. With testing, the designer prevents errors when the system has been used operationally which results in hampered the company's daily activities. In testing, the designer not only directs attention to the coding of the system but also the environment and ambiance of the system. Before carrying out testing, the person responsible for testing must understand the quality standards of what the test intends to do in order to achieve the appropriate testing results.

\subsection{Operational Maintenance}

Operational Maintenance is the activity of monitoring activities done within the system in order to maintain the performance of the system while the business runs, as usual, using a database system that has been developed. In addition to maintaining the performance of the database system, it is also necessary to collect the requirements for the next Database System Development Life Cycle.

Sadly, developing a database most likely requires knowledge on database technology and how it works, as well as its syntax and other information that is quite exclusive to the technological world [18-21]. But fortunately, as technology develops, studies and experts have come up with approaches that allow even people who are unfamiliar with database programming to create web applications and their databases easily. A few examples of the approaches said are model-driven [19, 21] and goal-driven approaches [22, 23].

\section{Discussion}

After analyzing the ongoing business processes, there are several problems that can be corrected to reduce the losses experienced by the company. Some of these problems are:
- Payroll costs are inflated because of fraud in recording attendance using only paper and pens without close supervision.

- The cost of paying overtime wages that are inflated due to fraud in recording overtime duration.

- The results of work that are not in accordance with the cost of salaries and overtime wages incurred (the progress of the project undertaken is not comparable with statements of overtime and work from employees).

- Frequent redundancy and inconsistencies in employee data, especially if there are changes in employee personal data or revisions to employee attendance data.

- HRD employees have difficulty finding data that has long been due to manual archive storage without the existence of a database that is a centralized company data storage.

Analysis of business processes that run at the company has exposed the needs of the company which is a database system for the management of the company's workforce. From the database system to be designed, the expectation of the organization is that the database system can fulfill the following:

- The database system can be the actual data storage regarding employee attendance (with the help of attendance machines). This means that the database system can read data in the extension format produced by the attendance machine.

- The database system can help HRD employees in data searching so that data search can be done quickly and accurately. This means that the database system must be able to display the data needed by HRD employees when HRD employees need them.

- To accelerate the manual recording transition to database system usage, the user interface of the database application that is designed is expected to be user-friendly so that it is easy for HRD employees to use to input and pull data output.

- The database system can store data without duplication, redundancy, and inconsistency, so the data drawn by HRD employees is the actual or most recent data.

Based on the problems and needs of the database system that has been described above, the author can suggest a solution which is making a database system for the management of the organization's human resource with the following explanation:

- Creating a database for the organization which will be a centralized data repository for all HRD operational activities of the organization such as employee personal data collection, employee attendance records, also the calculation of salaries received by employees.

- Making a prototype of a web-based application that will be a bridge for users (HRD employees of the organization) to input data into the database, process data, and also receive output information needed. 
By adopting the solution, the organization can feel some business values that can be beneficial for the organization, some of them are as follows:

- Can access the right data quickly, without inconsistencies and redundancy.

- Can reduce the burden of excessive salary and overtime pay that is not in accordance with the progress of the project being carried out because recording absences is difficult to commit fraud.

- HRD employees can process salaries faster and easier, without having to count them manually using a calculator every month.

\section{Conclusion}

Having an HR database is a necessity in a company, whether it is a global company or even a company with a smaller scope. Business processes that were running before the database system implementation brought many losses for the organization. This is because the manual recording that is easily done by employees who are absent. Employees who are absent can be easily recorded as attending. Employees who are not overtime can be recorded as overtime due to records that use paper and pens. This resulted in a very large expenditure on the part of employee salaries, which is not comparable with the progress of the organization This can be avoided if the organization uses an absent engine and database system that can ensure employee attendance data is accurate to the real situation. Without a proper HR database working as an HRIS, it would be a pain for the HR Manager to work on the employee data manually and produce the paycheck for each employee. Having an HRIS will ensure the data consistency and accuracy, thus resulting in accurate payroll calculation. For a more global approach, the DBMS used for this HRIS will be MySQL since it runs on a server and is web-based, allowing both interests to fit in, whether it is using localhost or the internet. This MySQL database will be accessed through a web-based application, which is another plus since now the human resource database can be accessed anywhere at any time, if the user has internet access and a device that can access websites through browsers. HR databases have been proven to be of help for a long time, however, to design an HR database for specific needs, there are several things that should be understood. These things are what databases are, what DBMS are and why we are choosing the DBMS we have chosen (in this case, MySQL), the Database Life Cycle which will be the overall guideline of the process.

\section{Conflict of Interest}

The authors declare no conflict of interest.

\section{Acknowledgment}

We thank Prof. Dr. Ir. Harjanto Prabowo, MM, as the Rector of Bina Nusantara University, Dr. Yohannes Kurniawan, S.Kom., S.E., M.MSI, as the Dean of Information Systems Faculty and Head of Information Systems Department, and Dr. Tanty Oktavia, S.Kom., MM, as the Head of Information Systems Study Program for all the support in the making and submission of this paper.

\section{References}

[1] E.W.T. Ngai F.K.T. Wat, "Human resource information systems: a review and empirical analysis. Personnel Review, Vol. 35 Iss 3, 297 - 314, 2006. doi: 10.1108/00483480610656702
[2] Z. Hussain, J. Wallace, N. E. Cornelius, "The use and impact of human resource information systems on human resource management professionals", Information \& Management, Vol. 44 Iss 1 pp. 74-89, 2007. doi: 10.1016/j.im.2006.10.006

[3] B. Schwartz, P. Zaitsev, V. Tkachenko, High-Performance MySQL, Third Edition, O'Reilly Media, Inc., 2012.

[4] S. Strohmeier, "Concepts of e-HRM consequences: a categorization, review and suggestion", The International Journal of Human Resource Management, 20:3, 528-543, 2009. doi: 10.1080/09585190802707292

[5] David Grant, Sue Newell, "Realizing the strategic potential of e-HRM", The Journal of Strategic Information Systems, 22:3, 187-192, 2013. doi: 10.1016/j.jsis.2013.07.001

[6] Beckers, A.M., Bsat, M.Z., "A DSS classification model for research in human resource information systems", Information Systems Management, Vol. 19 No. 3, 41-50, 2002. doi: 10.1201/1078/43201.19.3.20020601/37169.6

[7] Marler, J. H., Parry, E., "Human resource management, strategic involvement and e-HRM technology", The International Journal of Human Resource Management, 27(19), 2233-2253, 2015. doi 10.1080/09585192.2015.1091980

[8] Strohmeier, S., "Research in e-HRM: Review and implications", Human Resource Management Review, 17(1), 19-37, $2007 . \quad$ doi: 10.1016/j.hrmr.2006.11.002

[9] Stone, D. L., Deadrick, D. L., Lukaszewski, K. M., Johnson, R., “The influence of technology on the future of human resource management", Human Resource Management Review, 25(2), 216-231, 2015. doi: 10.1016/j.hrmr.2015.01.002

[10] Kovach, K.A., Hughes, A.A., Fagan, P., Maggitti, P.G., "Administrative and strategic advantages of HRIS", Employment Relations Today, Vol. 29 No. 2 , 43-8, 2002. doi: 10.1002/ert.10039

[11] Sadri, J., Chatterjee, V., "Building organizational character through HRIS", International Journal of Human Resources Development and Management, Vol. 3 No. 1, 84-98, 2003. doi: 10.1504/IJHRDM.2003.001048

[12] Bondarouk, T., Schilling, D., Ruël, H., "eHRM adoption in emerging economies: The case of subsidiaries of multinational corporations in Indonesia", Canadian Journal of Administrative Sciences / Revue Canadienne Des Sciences de l'Administration, 33(2), 124-137, 2016. doi: $10.1002 /$ cjas. 1376

[13] Satzinger, Jackson, Burd, System Analysis and Design with the Unified Process, Pearson, 2012.

[14] Connolly, T., Begg, C., Database System - A Practical Approach to Design, Implementation, and Management, Pearson, 2015.

[15] Haigh, I. D., Wadey, M. P., Gallop, S. L., Loehr, H., Nicholls, R. J., Horsburgh, K., Brown, J. M., Bradshaw, E., "A user-friendly database of coastal flooding in the United Kingdom from 1915-2014", Sci Data 2, 150021, 2015. doi: 10.1038/sdata.2015.21

[16] Fan, J., Li, G., Zhou, L., "Interactive SQL query suggestion: Making database user-friendly", In Proceedings of the 2011 IEEE 27th international conference on data engineering (ICDE '11), 351-362, Washington, DC, USA: IEEE Computer Society, 2011. doi: 10.1109/ICDE.2011.5767843

[17] Cross SS, et al., "How to design and use a research database", Diagnostic Histopathology, 2017. doi: 10.1016/j.mpdhp.2017.09.005

[18] Borges, C. R., Macías, J. A., "Feasible database querying using a visual enduser approach", In Proceedings of the 2nd ACM SIGCHI symposium on Engineering interactive computing systems (EICS '10)(pp. 187-192). New York, NY, USA: ACM, 2010. doi: 10.1145/1822018.1822047

[19] Brdjanin, D., Maric, S., "Towards the automated business model-driven conceptual database design", Advances in Databases and Information Systems Advances in Intelligent Systems and Computing, 186, 31-43, 2013.

[20] Deng, Y., Churcher, C., Abell, W., McCallum, J., "Designing a framework for end-user applications, end-user development", Lecture Notes in Computer Science, 6654, 67-75, 2011. doi: 10.1007/978-3-642-21530-8 7

[21] Fraternali, P., Comai, S., Bozzon, A., Toffetti, C. G., "Engineering rich internet applications with a model-driven approach", ACM Trans (p. 47), Web 4, 2, Article7, 2010. doi: 10.1145/1734200.1734204

[22] P. Nicolaos, T. Katerina, "Diagnosing user perception and acceptance using eye tracking in web-based end-user development", Computers in Human Behavior 27, 23-37, 2017. doi: 10.1016/j.chb.2017.02.035

[23] P. Nicolaos, T. Katerina, "Simple-talking database development: Let the enduser design a relational schema by using simple words", Computers in Human Behavior 48, 273-289, 2015. doi: 10.1016/j.chb.2015.02.002 